\title{
Student responses to vocabulary learning strategies on an ESAP course
}

\section{Clarke, Deborah C.}

2018-07

Clarke , D C 2018 , ' Student responses to vocabulary learning strategies on an ESAP course ' , ELT Journal , vol. 72 , no. 3 , pp. 319-328 . https://doi.org/10.1093/elt/ccy001

http://hdl.handle.net/10138/317796

https://doi.org/10.1093/elt/ccy001

unspecified

acceptedVersion

Downloaded from Helda, University of Helsinki institutional repository.

This is an electronic reprint of the original article.

This reprint may differ from the original in pagination and typographic detail.

Please cite the original version. 


\title{
Student responses to vocabulary learning strategies on an ESAP course
}

\author{
Deborah C. Clarke
}

Broadening vocabulary in a second language is often a key aim for students on language courses. This is especially the case for students who need to learn subject-specific academic vocabulary. There has been substantial research that focuses on the use of corpora for informing vocabulary instruction and materials development. However, selecting vocabulary from such lists and predicting the vocabulary gaps that students may have can be very challenging particularly when the students have diverse educational and professional backgrounds. In response to this, the present study proposes and explores attitudes in relation to the use of vocabulary learning strategies as part of a wider syllabus for students on an ESAP course. The findings of this research are particularly relevant to language teachers and course developers.

\section{Introduction}

Research has demonstrated that the relationship between vocabulary knowledge and, in particular, reading comprehension and fluency is symbiotic with levels of reading comprehension increasing as vocabulary knowledge broadens and vice versa (Nation 2012; Schmitt, Jiang \& Grabe 2011). With this in mind, it is no surprise that university students, who have high reading loads, often report that broadening vocabulary knowledge is of particular concern (Durrant 2014: 328) and teachers often regard their role as assisting their students in vocabulary development, especially in ESP contexts (Hyland \& Tse 2007: 236). One way of managing the challenge of incorporating vocabulary instruction into academic English courses is to provide students with independent vocabulary learning tasks, which, in the higher education environment, are frequently based on corpora, such as Coxhead's (2000) Academic Word List (AWL).

It is clear that corpora such as the AWL are, in general, a valuable tool for informing vocabulary instruction. However in their evaluation of the AWL, Hyland and Tse (op.cit.) found that many of the vocabulary items were infrequent in the sub-disciplines, most of the words were unevenly distributed and the meanings of individual words varied across the disciplines. Similarly, Durrant's (ibid.) analysis of the British Academic Written English corpus (BAWE) showed that less than 50 per cent of the vocabulary among the different disciplines could be considered generic and, if a word is generic, it is only used in the same way in less than 50 per cent of the instances. His results also demonstrated that within the disciplines undergraduate-level vocabulary usage was quite distinct from vocabulary usage at master's degree level. These studies suggest that a single academic vocabulary corpus is insufficient for the construction of a general syllabus and point to the need for discipline and even level-specific corpora.

The current research was conducted with in-sessional ESAP law students from the University of Helsinki Language Centre for whom the construction of a discipline- and level-specific corpus is not practical. This is because, apart from the resources and skills required for producing such a corpus, the profiles of these students are particularly 
diverse. To be more specific, the students are not given a level test before they are placed on a course. Furthermore, they are not placed according to their year of study; consequently, they could be in their first year or fifth year, and many are often already working within their field. This means that they arrive on language courses with very varied vocabulary knowledge and needs. To manage this situation a component of explicit instruction on vocabulary learning strategies rather than vocabulary items was added to the syllabus to enable the students to expand their vocabulary in an individualized way.

The academic research that supports the use of vocabulary learning strategies to broaden vocabulary is reasonably extensive. According to Grabe (2009: 276), most researchers of vocabulary agree that learning vocabulary effectively involves instruction on developing word-learning strategies. Word-learning strategies are considered to be important for explicitly activating vocabulary, because they require a conscious effort on the part of the learner to notice and select new items, to infer meaning from context and to transfer and store new items in the long-term memory (Ellis 1994 as cited in Pavičić Takač 2008: 17). Furthermore, teaching learning strategies, or self-regulating learning, tends to be motivating for students because it allows student autonomy (Dörnyei 2003: 16) and encourages students to continue learning beyond any given course (Pavičić Takač ibid.: 24).

On the course featured in this study, Schmitt's (1997) taxonomy of vocabulary learning strategies is used to help students reflect on their current practices and to highlight the range of vocabulary learning strategies available to them. Schmitt's (ibid.) taxonomy is divided into two broad categories; vocabulary learning strategies that can be used without expert help, or determination strategies, and consolidation strategies that may require specific instructions and guidance. These categories can also be perceived, respectively, as strategies to be employed when encountering a word and those useful to assist in retaining the meaning of a word. Within the consolidation category are further sub-categories, namely, metacognitive strategies, which refer to strategies where the learner has developed the ability, based on a knowledge of their learning preferences, to regulate and plan for their learning; cognitive strategies that are more mechanical in nature, such as simple repetition that does not involve any manipulation of the target vocabulary and social/ affective strategies that involve the use of interpersonal relationships and overcoming emotional barriers to learning (O'Malley \& Chamot 1990 as cited in Schmitt: ibid.).

The cognitive strategies that are associated with rote learning such as written and verbal repetition seem to be more commonly used by students (Schmitt ibid.). In the present setting, such strategies certainly seem to feature strongly in the students' repertoire of vocabulary learning strategies. Grabe (op.cit.) argues that the cognitive strategies, which are often derided in favour of more technical strategies, can indeed be effective. In fact, a recent study conducted at an Iranian university (Atasheneh \& Naeimi 2015) tested the efficiency of using the cognitive strategies of flashcards and a learning notebook and found that the use of these strategies led to statistically significant vocabulary gains when compared to explicit instruction on vocabulary. The main argument against cognitive strategies is that they provide limited retention of target vocabulary items without frequent revision (Klapper 2008).

The most effective strategies for vocabulary consolidation appear to be memorisation strategies. The memorisation strategies that are associated with Dual Coding Theory 
(DCT) (Sökmen 1997) seem to be popular with vocabulary researchers perhaps because they are associated with deeper learning when compared with cognitive strategies. DCT draws upon the ability of stimuli to evoke imagery; for example, the mnemonic Peg method uses rhymes, for instance three pea, four door, alongside mental images to visualize the meanings; the Loci Method involves associating target vocabulary with mental images of landmarks on a known route, such as the journey home from work; and the Keyword Method involves associating acoustically similar vocabulary items from L1 and L2 alongside the use of visualisation; for example, the Finnish word laulaa (to sing) can be combined with the phonologically similar English word 'lawyer' and the mind's eye can create an image of a singing lawyer. The success of such methods, however, rely upon students' ability to conjure imagery in addition to the potential effect of cultural background (Pavičić Takač op.cit.). Nevertheless, training in these more complex and manipulative methods has been shown to be more effective in terms of the retention of words (Pressley et al. 1982 as cited in Pavičić Takač ibid.).

After being exposed to the different strategies, learners will adopt those that best suit them in relation to, for example, cultural and affective factors, age and maturity and language proficiency. The purpose of this current research is not to measure the vocabulary gains made by the students according to their chosen methods, but to gain insight into their attitudes to learning vocabulary consolidation strategies. The question being addressed is:

How will the students respond both affectively and cognitively to the learning of vocabulary consolidation strategies on the course?

\section{The course}

The course in which the present research took place is a compulsory credit-rated ESAP course for law students who can be at bachelor's or master's level. A skills-based curriculum is provided for the course and it focuses on reading, discussion and life-long learning. The course revolves around a group Reading and Discussion Assignment for which the students choose an academic or professional text from their field, and then 1) write a glossary for the text, 2) create a vocabulary activity, 3) write some comprehension questions and finally 4) write some questions for discussion on the topic of the text. Once the assignment has been prepared, each group of students has approximately 60 minutes to present and set their tasks for the class. Apart from fulfilling the curriculum requirements of practising skills in reading and discussion, the rationale for the assignment is that by choosing texts from within their field the students' motivation for learning will be heightened. Selecting such texts also ensures that any general learning about law and the associated legal and academic vocabulary is fully contextualized.

The two vocabulary tasks within the assignment both support the class in comprehending and noticing new vocabulary items and provide a pool of vocabulary that the students can draw upon for the planned element of vocabulary learning. The vocabulary learning component of the course is supported inside the classroom, but the learning of the vocabulary is done outside the classroom. The vocabulary learning 
aspect of course runs alongside the main assignment and is organized in the following way:

\section{Research methods and participants}

The present study features two cohorts of a seven-week ESAP law course. There were 10 students in the first cohort and 21 in the second cohort. The first group had two two-hour meetings a week and second group met once a week for four hours.

At the end of the two courses, willing students took part in focus group interviews that provided the opportunity to reflect upon their experiences of using vocabulary learning strategies. Of the ten students who had taken the first course, eight participated in the focus group ( 2 male and 6 female with an age range of 19 to 25 years old). Six of the 21 students took part in the second focus group ( 2 male and 4 female with an age range of 21 to 24 years old). Two additional female course participants ( 22 and 27 years old) answered the focus group questions by e-mail after a misunderstanding about the timing of the second focus group. Their responses have been included in the analysis.

Focus group interviews were chosen because, in addition to fitting with the curriculum of the course in terms of discussion, it was felt that focus groups would yield richer responses than, for example, a questionnaire. The advantages that focus groups have over the individual interviews and potentially other qualitative methods are, according to Hess (1968 as cited in Vaughn, Schumm \& Sinagub 1996), their ability to extend the emerging data through group synergy, allow participants to comment on each other's ideas, generate some excitement about the topic, allow spontaneity so that participants respond when they wish and do not have to respond to every question and, finally, when the group feels comfortable participants can be more candid in their responses.

The procedure for the focus groups in this study followed the guidelines specified by Vaughn et al. (ibid.) very closely. An audio and visual-audio recording was taken of both focus groups so that they could be transcribed and non-verbal communication observed. Participants gave informed consent and were able to specify which data they would allow for research purposes: written transcription, audio extracts and/ or video extracts. In addition, at the closing of the focus group they were asked not to discuss the nature of the discussion in order to ensure the anonymity of the individual members.

The video was listened to more than once and the transcription was read and reread in order to allow greater intimacy with the data (Saldaña 2001). Next, the transcriptions were analysed sentence-by-sentence and labelled with the descriptive codes, mostly in the form of single nouns, that capture the essence of the sections of data. Importantly, descriptive codes are considered suitable for both interview and document data (Saldaña ibid.) which enabled the inclusion of the two responses received by email. When the codes were finalized, categories were formed by making connections between the codes. To exemplify, the codes 'reward', 'novelty', 'creativity', 'social interaction' and 'co-learning' merged to form the category 'pleasure'. The next step involved writing analytic memos which are short pieces of writing that make sense of the relationships between the codes and the categories. This stage is important for allowing the researcher to identify patterns and take a broader view of the data (Saldaña ibid.: 90). 


\section{Findings}

The responses that the students had to the learning of vocabulary consolidation strategies represent affective or emotional responses, such as pleasure, cognitive or intellectual responses, such as changes in strategy, and active responses where an action is taken. Through the process of coding the focus group data, five categories that encapsulate the reactions of the students to learning vocabulary strategies emerged: pleasure, motivation, time, reflection and failure. The students' reactions are reported verbatim with the exception of false starts. The italicized words in this section denote the codes included in each category.

\section{Pleasure}

The responses that were merged to create the category of pleasure concern reward gained through achievement; for example, this student shared her experience of using flash cards:

... [it's] really rewarding to notice that I am actually learning words and I can discard some cards I don't need anymore because I know the words. It's pleasant

Whilst flashcards were a tried-and-tested strategy for this student, others enjoyed the novelty of the new learning methods, such as the Keyword method, and the creativity found in constructing example sentences to include their target vocabulary:

it's a bit creative because you know it activates some areas of the brain when you come up with new sentences

Social interaction and the space that was created for co-learning were also valuable for these students:

We help each other and then we use those word so, it's good to hear a word another from peer's mouth when he or she pronounces it and then you read it so there's like double learning

This student was reflecting on the discussion component of the course assignment (see The Course section) where he used the vocabulary encountered in the glossaries and the texts with other students.

\section{Motivation}

Those students who found pleasure in the vocabulary learning process were engaged and motivated, but others found motivation problematic without strong external pressure:

I think that I should study for myself but if there was an exam I think I would study harder... 
Another student found it difficult to find the self-discipline to follow through with his chosen strategy:

I was planning to test myself with words lists but I didn't find motivation to do that

Others found getting into a routine difficult but hoped to continue with vocabulary learning after the course:

I hope I used the semantic maps one day [aspiration]

\section{Time}

The students that had difficulty motivating themselves often mentioned the amount of time they had as a factor in their failure to engage properly with the vocabulary learning process:

I like strategy with cards but it requires a lot of time

Others who found the process motivating were successful and had developed time management strategies:

I have success in this because I often opened my notes with new words in the public transport to memorize them

Others commented upon the speed of the different strategies and made choices based on how time efficient they found certain methods:

I do like mental repeating so I repeat a word in my head and try to ... remember the how to write things correctly because it's faster and efficient

However, as is the case with this example, the faster strategies tend to be cognitive strategies with reportedly lower levels of long-term retention (Klapper, op.cit.).

\section{Reflection}

Some students, rather than focusing on time, were thoroughly engaged in the process and readily analysed the shortcomings of their existing strategies leading to a change in strategy, for example one student changed her existing determination strategy:

I will technically switch to a monolingual dictionary

Others had become entirely autonomous. Rather than using the glossaries from the course assignment (see The Course section), some students focused on words from their main law courses and one student showed independence by:

also [making] my own word lists because I thought it was more useful than learn words from a given word list

For these students, the effectiveness of vocabulary learning methods are considered to be those which require forethought and concentration, because it would lead to better learning: 
Composing new sentences was also a good method for me because then you'd really have to concentrate on use the word in the right way

\section{Failure}

For others the amount of effort required to experiment with and evaluate the learning strategies led to feelings of failure:

I did not do as much as I was able to do and did not try all strategies that teacher acquaint me with

Some students, however, avoided the extra effort in that they were reluctant to take the risk of learning new strategies because they did not want to compromise their learning and in this way they avoided the possibility of failure

For most students, however, the feeling of failure was mixed with feelings of guilt about not achieving vocabulary learning goals:

Well it was because I didn't do enough so it was just my fault. I could've done more

This was an unfortunate outcome of the process that was later better managed through the goal-setting process.

\section{Discussion}

\section{Differences between the groups in the study}

The previous section combined the two groups of students in the present study, but there were two notable differences between these groups which are relevant for course planners. Firstly, the group that met twice a week structured the teacher's role in monitoring the progress they had made with vocabulary learning as encouraging. In contrast, a small number of students from the group who met once a week expressed some frustration about this aspect of the course because it felt repetitive. Nevertheless, during the focus group interviews, one of these particular students also commented that "the most important thing [a] teacher brings in the vocabulary learning is discipline, [and] that there is somebody who checks on your process and will ask you 'well did you do this?' is useful". This suggests that the time set aside for monitoring vocabulary learning is useful but should not occur in every lesson so as to avoid disengagement with the process. This marks a slight departure from Sökmen's (op.cit.) recommendation of dedicating ten minutes per class, one session per week or continual work outside of class for vocabulary learning. One way to manage this potential affective barrier is to review vocabulary learning both in the classroom and remotely with the use of technology so that the reviewing process can feel less routine. Another way is to vary the review tasks more so that the reviewing of the vocabulary learning strategies never occurs in the same lesson as the reviewing of the vocabulary items.

Another point of disagreement between the two focus groups was the overall usefulness of vocabulary learning strategies. The group who met twice a week were unanimous in 
their opinion that the teaching and learning of vocabulary consolidation strategies was useful. However, within the group that met once a week, two of the students did not find the strategies useful and one was undecided. It may be that the limited number of seven meetings with this group was insufficient to develop a curiosity for words and word learning that, according to Grabe (op.cit.: 284), is necessary for effective vocabulary learning.

\section{Key themes highlighted by this study}

Analysis of the focus group interviews demonstrated the importance of overcoming and providing for the affective dimensions of vocabulary learning. It was clear that the students found the experience of co-learning a motivating factor in the learning process and enjoyed the creativity and novelty involved in using the new vocabulary learning strategies. At the same time, concurring with Klapper's (op.cit) assertion that rote learning practices are reassuring, it was important for these students to be given the freedom to use their trusted, often more mechanical methods in parallel. Even when they did not try some of the more experimental methods they seemed to feel informed enough to be able to employ such methods after the course.

Some students expressed their disappointment with not having done more during the course to broaden their vocabulary which led to feelings of failure. This outcome is one that Pavičić Takač (op.cit.) advises instructors to consider at the planning stage. To overcome this, it is important to give the students freedom to alter vocabulary learning goals so that they are achievable. It is my feeling that some of the students in the present study had underestimated the effort involved in expanding their professional and academic vocabulary. Consequently, raising greater awareness of this would be a useful addition to a vocabulary learning syllabus.

Another factor emerging from the analysis of the focus group data concerned the cognitive processes related to knowing and understanding. The students in the present study were competent at evaluating their own practices, because they had clearly reflected on how and what they were learning, and then altering their practices accordingly. To exemplify, the use of word lists that seemed to be a trusted method was revaluated and the students were able to discuss together the advantages and disadvantages of such rote learning and how they could employ the advantages of such methods effectively. This perhaps would not have occurred without the provision of time and space on the course to review their learning goals and strategies together and without being encouraged by the teacher to change their practices to suit their own style and situation.

Concurring with the majority of researchers of vocabulary (Grabe ibid.), the students also highlighted the importance of contextualized vocabulary and appreciated that context was always provided through the course assignments. The students demonstrated differing levels of confidence with choosing their own vocabulary to focus on, however. One student strongly suggested that incidental learning of vocabulary rather than learnt vocabulary suited her best, whereas others despite all of the learning strategies and materials on the course felt that the teacher was best placed to select the vocabulary for learning. Whilst this is of course possible, it exposes the difficulties that Durrant (op.cit.) mentioned EAP teachers face as they are often not subject specialists. The course has continued after this study and, drawing upon Sökmen's (op.cit.) 
guidelines intended for teachers, there has been greater emphasis and instruction on compiling glossaries which seem to have given the students greater confidence in selecting their own vocabulary.

\section{Conclusion}

Students can join university language courses with differing degrees of professional and academic experience. The aim of the current study was to share a way of teaching and learning vocabulary that recognizes this. The learning method presented here can act as a complement or alternative to constructing a vocabulary syllabus from corpora. To gather responses to the method, focus groups were conducted with some students who had participated in a course that focused on vocabulary consolidation strategies.

The results suggest that while a framework in the form of a structured course with clear pedagogical direction needs to exist, choice and flexibility in learning strategies is also necessary to meet the affective and cognitive demands of the students. To exemplify, whereas the use of the memory strategies from Schmitt's (op.cit) taxonomy inspired the students, the cognitive strategies that had served them in the past provided reassurance during the learning process. Furthermore, to promote lifelong and autonomous learning, regular opportunities for reflection on learning strategy are needed as these can promote evaluation of learning goals and strategies that have the potential to carry the students' learning beyond the course.

Final version received November 2017

\section{$\underline{\text { Notes }}$}

1 The vocabulary learning questionnaire was developed using the rubric from Oxford's (1990) widely used SILL questionnaire and Schmitt's (op.cit.) taxonomy of vocabulary learning strategies. This can be requested via email from the author.

2 The notebook method was taught in the way described by Schmitt and Schmitt (1995 cited in Pavičić Takač, op.cit.)

\section{References}

Atasheneh, N. and Naeimi, M. 2015. 'Vocabulary Learning through Using Mechanical Techniques Vocabulary Learning Strategy'. Theory and Practice in Language Studies 5/ 3: 541-548.

Coxhead, A. 2000. 'A New Academic Word List'. TESOL Quarterly 34/ 2: 213-238.

Dörnyei, Z. 2003. 'Attitudes, orientations, and motivations in language learning: advances in theory, research, and applications'. Language learning 53/ 1: 3-32.

Durrant, P. 2014. 'Discipline and Level Specificity in University Students' Written Vocabulary'. Applied Linguistics 35/ 3: 328-356. 
Grabe, W. 2009. Reading in a Second Language: Moving from Theory to Practice. Cambridge: Cambridge University Press.

Hyland, K. and Tse, P. 2007. 'Ts There an "Academic Vocabulary"'? TESOL Quarterly 41/ 2: 235253.

Klapper, J. 2008. 'Deliberate and Incidental: Vocabulary Learning Strategies in Independent Second Language Learning' in T. Lewis and S. Hurd (eds.) Language Learning Strategies in Independent Settings. Bristol, UK: Multilingual Matters.

Nation, I. S. P. 2012. Learning Vocabulary in Another Language (Second edition). Cambridge: Cambridge University Press.

Oxford, R. L. 1990. Language Learning Strategies: What Every Teacher Should Know. New York: Newbury House Publishers.

Pavičić Takač, V. 2008. Vocabulary Learning Strategies and Foreign Language Acquisition. Bristol, UK: Multilingual Matters.

Saldaña, J. 2011. Fundamentals of Qualitative Research. Oxford: Oxford University Press.

Schmitt, N. 1997. 'Vocabulary Learning Strategies' in N. Schmitt and M. McCarthy (eds.) Vocabulary: Description, Acquisition and Pedagogy. Cambridge: Cambridge University Press.

Schmitt, N., Jiang, X. and Grabe, W. 2011. 'The Percentage of Words Known in a Text and Reading Comprehension'. The Modern Language Journal 95/ 1: 26-43.

Sökmen, A. J. 1997. 'Current trends in teaching second language vocabulary' in N. Schmitt and M. McCarthy (eds.). Vocabulary: Description, Acquisition and Pedagogy. Cambridge: Cambridge University Press.

Vaughn, S, Schumm, J, and Sinagub, J. 1996. Why use focus group interviews in educational and psychological research? Thousand Oaks: SAGE Publications.

\section{The author}

\section{Email: deborah.clarke@helsinki.fi}

Deborah Clarke joined the University of Helsinki Language Centre in 2015 where she is a University Instructor in academic and professional English. She has taught EAP and ESOL in the UK and EFL in Spain and New Zealand. Her professional interests include ESAP syllabus and materials development and inclusive education. 